\title{
ESTUDO DAS PROPRIEDADES FÍSICO-MECÂNICAS DE MASSAS CERÂMICAS INCORPORADAS COM CHAMOTE*
}

\author{
Alexandre Magno Alves de Oliveira ${ }^{1}$ \\ Luis Sérgio Peixoto Pessanha ${ }^{2}$ \\ Wellington Fernandes Junior ${ }^{3}$ \\ Israel Nelo Nunes ${ }^{4}$ \\ Jonas Alexandre \\ Afonso Rangel Garcez de Azevedo ${ }^{6}$ \\ Sergio Neves Monteiro ${ }^{7}$
}

\section{Resumo}

Os resíduos provenientes das indústrias cerâmicas demandam locais apropriados de descarte, gerando gastos, desperdício de matérias-primas e, quando o local de descarte é impróprio, problemas ambientais. Sendo assim, se faz necessário o estudo da reutilização destes resíduos, tanto para fins econômicos quanto ambientais. Dessa forma, a reutilização de chamote, resíduo oriundo do descarte de materiais cerâmicos, é possível através da sua incorporação em massas cerâmicas para a produção de novos materiais (blocos, tijolos, telhas, etc). O presente trabalho teve como objetivo analisar a influência do chamote em massas cerâmicas, comparando dosagens com substituição de $10 \%, 20 \%$ e $30 \%$ em massa com um traço de referência. Para isso foram realizados ensaios, com os quais pode-se obter as propriedades relacionadas a retração por secagem e por queima, absorção de água, perda ao fogo, porosidade aparente e tensão de ruptura à flexão. Em suma, pode-se concluir que o uso do chamote permite a obtenção de materiais com boa resistência mecânica, moderada absorção de água e com boas propriedades dimensionais, demonstrando ser uma alternativa ambientalmente amigável e economicamente viável.

Palavras-chave: Resíduo; Massa cerâmica; Chamote.

\section{STUDY OF THE PHYSICAL-MECHANICAL PROPERTIES OF CERAMIC MASS INCORPORATED WITH GROG}

\section{Abstract}

Residues from the ceramic industries require appropriate disposal sites, generating waste, waste of raw materials and, where the disposal site is improper, environmental problems. Therefore, it is necessary to study the reuse of these wastes, both for economic and environmental purposes. Thus, the reuse of chamote, residue from the disposal of ceramic materials, is possible through its incorporation in ceramic masses for the production of new materials (blocks, bricks, tiles, etc.). The objective of the present work was to analyze the influence of chamote on ceramic masses, comparing dosages with substitution of $10 \%, 20 \%$ and $30 \%$ by mass with a reference trace. For this, tests were carried out, with which properties related to retraction by drying and firing, water absorption, fire loss, apparent porosity and bending rupture stress can be obtained. In short, it can be concluded that the use of chamote allows the obtaining of materials with good mechanical resistance, moderate water absorption and good dimensional properties, proving to be an environmentally friendly and economically viable alternative.

Keywords: Residue; Ceramic mass; Grog.

1 Engenharia Civil, Mestrando em Estruturas, Laboratório de Engenharia Civil, Universidade Estadual do Norte Fluminense (UENF), Campos dos Goytacazes, Rio de Janeiro, Brasil.

2 Engenharia Civil, Mestrando em Estruturas, Laboratório de Engenharia Civil, Universidade Estadual do Norte Fluminense (UENF), Campos dos Goytacazes, Rio de Janeiro, Brasil.

3 Engenharia Civil, Mestrando em Estruturas, Laboratório de Engenharia Civil, Universidade Estadual do Norte Fluminense (UENF), Campos dos Goytacazes, Rio de Janeiro, Brasil.

4 Graduando em Engenharia Civil, Bolsista de Iniciação Científica, Laboratório de Engenharia Civil, Universidade Estadual do Norte Fluminense (UENF), Campos dos Goytacazes, Rio de Janeiro, Brasil. 
5 Engenharia Civil, Doutor, Professor Associado, Laboratório de Engenharia Civil, Universidade Estadual do Norte Fluminense (UENF), Campos dos Goytacazes, Rio de Janeiro, Brasil.

6 Engenharia Civil, Doutorando em Estruturas, Laboratório de Engenharia Civil, Universidade Estadual do Norte Fluminense (UENF), Campos dos Goytacazes, Rio de Janeiro, Brasil.

7 Engenharia Metalúrgica, Doutor, Professor Titular, Laboratório de Ciência dos Materiais, Instituto Militar de Engenharia (IME), Rio de Janeiro, Rio de Janeiro, Brasil.. 


\section{INTRODUÇÃO}

Ao visitar uma indústria cerâmica, nota-se que grande quantidade de blocos cerâmicos são perdidos devido a defeitos de fabricação. Em contrapartida, cada dia mais estudos e pesquisas estão sendo realizadas para que as produções industriais sejam o mais sustentáveis possível e que alcancem desperdícios cada vez mais próximos a zero. Em se tratando de produtos cerâmicos, seus constituintes não são tóxicos, mas a grande geração de descarte acarreta em prejuízo econômico e sobretudo ambiental.

O setor de serviços e da indústria relacionados à construção civil, correspondem a uma fatia importante da economia, por isso, investir em formas que otimizem e melhorem as produções sempre serão válidas. O próprio setor da indústria cerâmica é responsável por grande número de empregos e recursos para os locais próximos a seus pólos. A região de Campos dos Goytacazes - RJ é um dos principais pólos cerâmicos do Brasil, com dezenas de indústrias cerâmicas, portanto o estudo sobre uso do seu descarte é de extrema valia para a região, mediante os aspectos financeiros e principalmente os ambientais.

Com a otimização de processos de produção e a capacitação técnica de funcionários, as linhas de produção tendem a diminuir suas perdas. Quando se analisa a indústria cerâmica, por se tratar de produtos frágeis, os rejeitos sempre existirão, tanto na conformação quanto no transporte, portanto, estudar as formas de utilização do material de descarte é uma alternativa muito interessante.

Existem hoje, uma infinidade de pesquisas relacionadas à incorporação de resíduos, dos mais variados tipos, em produtos da construção civil, que são testados como substituição de solos, cimento e agregados em argamassas, concreto e até blocos cerâmicos. A incorporação do resíduo de bloco cerâmico, denominado chamote, na composição de outros novos blocos, é uma solução viável tanto no aspecto econômico quanto no ambiental, pois através da reutilização, há redução de matéria prima necessária, reduzindo-se extrações e minimizando problemas ambientais, causados pelo despejo do resíduo, em local, muitas vezes, não apropriado.

A influência do chamote na nova peça cerâmica, uma vez que este já foi queimado, será resposta da nova temperatura de queima, podendo agir somente na melhora do grau de empacotamento e manter-se inerte ou, se exposto a temperaturas mais altas a que foi submetido, poderá sinterizar-se com o restante do material.

Neste trabalho foi realizado um estudo experimental observando o efeito da incorporação do chamote disponibilizado por uma indústria cerâmica local em massas cerâmicas, para a fabricação de blocos de vedação, observando e comparando os valores obtidos com um traço sem a incorporação do resíduo.

Este trabalho tem como objetivo julgar o efeito da incorporação do chamote em massas cerâmicas dosadas em diferentes proporções, e analisar o efeito da temperatura, queimas a 850 e $950^{\circ} \mathrm{C}$, analisando as propriedades de retração por secagem e por queima, absorção de água, perda ao fogo, densidade e porosidade aparente e tensão de ruptura à flexão. 


\section{MATERIAIS E MÉTODOS}

Para a realização deste trabalho, foram utilizados argila e chamote provenientes da indústria cerâmica Sardinha, situada na cidade de Campos dos Goytacazes - RJ, que é um dos principais polos cerâmicos do Brasil. O chamote foi obtido do descarte de blocos cerâmicos com temperatura final de queima de aproximadamente $850^{\circ} \mathrm{C}$.

A amostra de chamote coletada foi triturada manualmente e moída em moinho de bolas, já a argila foi triturada mecanicamente, após isso, foram destorroados em almofariz de porcelana e passados na peneira ABNT200, separouse uma pequena porção de cada para análises, a saber, difratometria e eflorescência de raios-X (DRX, EDX), análise térmica diferencial (DTA) e termogravimetria derivada (DTG). Para a caracterização granulométrica foram passados na peneira ABNT40.

Para a elaboração dos corpos de prova o chamote e a argila foram passados na peneira ABNT10, e então confeccionou-se os corpos de prova nas seguintes porcentagens, a saber, $0 \%, 10 \%, 20 \%$ e $30 \%$ de substituição parcial de argila por chamote, conforme a tabela I. Foram confeccionados 30 corpos de prova por extrusão em maromba a vácuo, nas dimensões $120 \times 30 \times 20 \mathrm{~mm}$ (comprimento, largura e altura) para cada porcentagem, totalizando 150 corpos de prova. Separouse uma quantidade de cada traço, a seco, para a realização de análises (DTA, DTG e caracterização granulométrica).

Tabela I - Composição das amostras.

\begin{tabular}{|c|c|c|c|c|}
\hline Composição & C0 & C1 & C2 & C3 \\
\hline Argila (\%) & 100 & 90 & 80 & 70 \\
\hline Chamote (\%) & 0 & 10 & 20 & 30 \\
\hline
\end{tabular}

Após se medir o comprimento e massa dos corpos confeccionados, foram colocados durante 24 horas para descansar a condições ambientes. Após isso, foram colocados em estufa MA033/1 a $100{ }^{\circ} \mathrm{C}$ por $24 \mathrm{~h}$, e então mediu-se 0 comprimento e massa, observando sua retração por secagem. Dos 30 corpos de prova de cada traço, 15 foram para queima em forno Mufla, modelo ML 1300, à 850 ${ }^{\circ} \mathrm{C}$ e 15 à $950^{\circ} \mathrm{C}$. Após a queima, forma medidos o comprimento e massa das amostras, obtendo-se os valores de retração por queima e perda ao fogo.

Depois da queima, foram separados 7 corpos de prova, dos 15 de cada traço e temperatura de queima, para serem ensaiados a flexão e os 8 restantes para medir a absorção de água.

A retração linear foi determinada através dos comprimentos iniciais e finais dos corpos de prova após a secagem e a queima, para as temperaturas de $850 \mathrm{e}$ $950^{\circ} \mathrm{C}$. A porosidade aparente e a absorção de água foram obtidas a partir dos procedimentos estabelecidos na NBR 15270-1 [3]. A perda ao fogo foi determinada a partir das massas dos corpos de prova antes e depois do processo de queima. A tensão de ruptura foi encontrada através do procedimento de flexão a 3 pontos, utilizando uma prensa universal modelo EMIC 23-30. 


\section{RESULTADOS E DISCUSSÃO}

\subsection{Composição química}

De acordo com a tabela II, a sílica $\left(\mathrm{SiO}_{2}\right)$, tanto na argila como no chamote, é o principal constituinte, com percentuais de $55,69 \%$ e $58,42 \%$ para a argila e para o chamote, respectivamente. A alumina $\left(\mathrm{Al}_{2} \mathrm{O}_{3}\right)$ apresentou na argila o percentual $34,59 \%$ e $31,47 \%$ no chamote. Os valores de hematita $\left(\mathrm{Fe}_{2} \mathrm{O}_{3}\right)$ foram próximos para ambas amostras. Foram identificados baixos teores de óxidos alcalinos $\left(\mathrm{K}_{2} \mathrm{O}\right)$ e alcalinos terrosos $(\mathrm{CaO})$. O chamote foi obtido do descarte de blocos cerâmicos confeccionados com a mesma argila do estudo, isto pode explicar, a similaridade dos elementos e percentuais.

Tabela II - Composição química da argila e do chamote.

\begin{tabular}{|l|l|l|l|l|l|l|l|}
\hline Amostra & $\mathrm{SiO}_{2}$ & $\mathrm{Al}_{2} \mathrm{O}_{3}$ & $\mathrm{Fe}_{2} \mathrm{O}_{3}$ & $\mathrm{~K}_{2} \mathrm{O}$ & $\mathrm{SO} 3$ & $\mathrm{TiO}_{2}$ & $\mathrm{CaO}$ \\
\hline Argila & 55,69 & 34,59 & 4,15 & 1,81 & 1,64 & 1,23 & 0,75 \\
\hline Chamote & 58,42 & 31,47 & 3,17 & 2,86 & 1,61 & 1,23 & 1,16 \\
\hline
\end{tabular}

\subsection{Análise Granulométrica}

Estão representadas na tabela III as frações dos materiais encontradas para as diferentes composições.

Tabela III - Frações dos materiais

\begin{tabular}{|c|c|c|c|c|c|c|c|c|c|c|}
\hline \multirow[b]{2}{*}{$\mathrm{n}^{0}$} & \multirow[b]{2}{*}{$\begin{array}{c}\text { Argila } \\
(\%)\end{array}$} & \multicolumn{3}{|c|}{ Pedregulho } & \multicolumn{3}{|c|}{ Areia } & \multirow[b]{2}{*}{ Silte } & \multirow[b]{2}{*}{ Argila } & \multirow[b]{2}{*}{$\begin{array}{c}\text { Classificação } \\
\text { USCS }\end{array}$} \\
\hline & & $\begin{array}{l}\text { \& } \\
\mathscr{N} \\
\text { ㅍ }\end{array}$ & $\begin{array}{l}\frac{.0}{0} \\
\sum^{\oplus}\end{array}$ & $\stackrel{\circ}{=}$ & 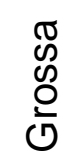 & $\begin{array}{l}\frac{\pi}{0} \\
\sum_{2}^{\infty}\end{array}$ & 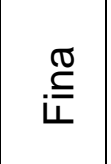 & & & \\
\hline C3 & 70 & - & - & - & 0,7 & 5,5 & 26,4 & 37,3 & 30,2 & $\mathrm{MH}$ \\
\hline C2 & 80 & - & - & - & 0,3 & 5,5 & 16,9 & 33,3 & 44,1 & $\mathrm{MH}$ \\
\hline C1 & 90 & - & - & - & 0,3 & 4,5 & 17,7 & 31,7 & 45,7 & $\mathrm{CH}$ \\
\hline CO & 100 & - & - & 1,0 & 7,2 & 16,7 & 11,8 & 13,8 & 49,6 & $\mathrm{CL}$ \\
\hline $\mathrm{CH}$ & 0 & - & - & - & - & 0,2 & 22,1 & 68,8 & 9,0 & SM \\
\hline
\end{tabular}

As distribuições granulométricas das diferentes composições estão ilustradas na figura 1 , onde pode-se observar que à medida que foi adicionado os percentuais de chamote $(\mathrm{CH})$, decresceram o percentual de argilas e consequentemente aumentaram o de silte. Com o resultado obtido, nota-se que os percentuais de argila, silte e areia das composições, tem uma proporção inferior ao recomendado, que é de $60 \%$ de argila, $40 \%$ de silte e areia [1]. 


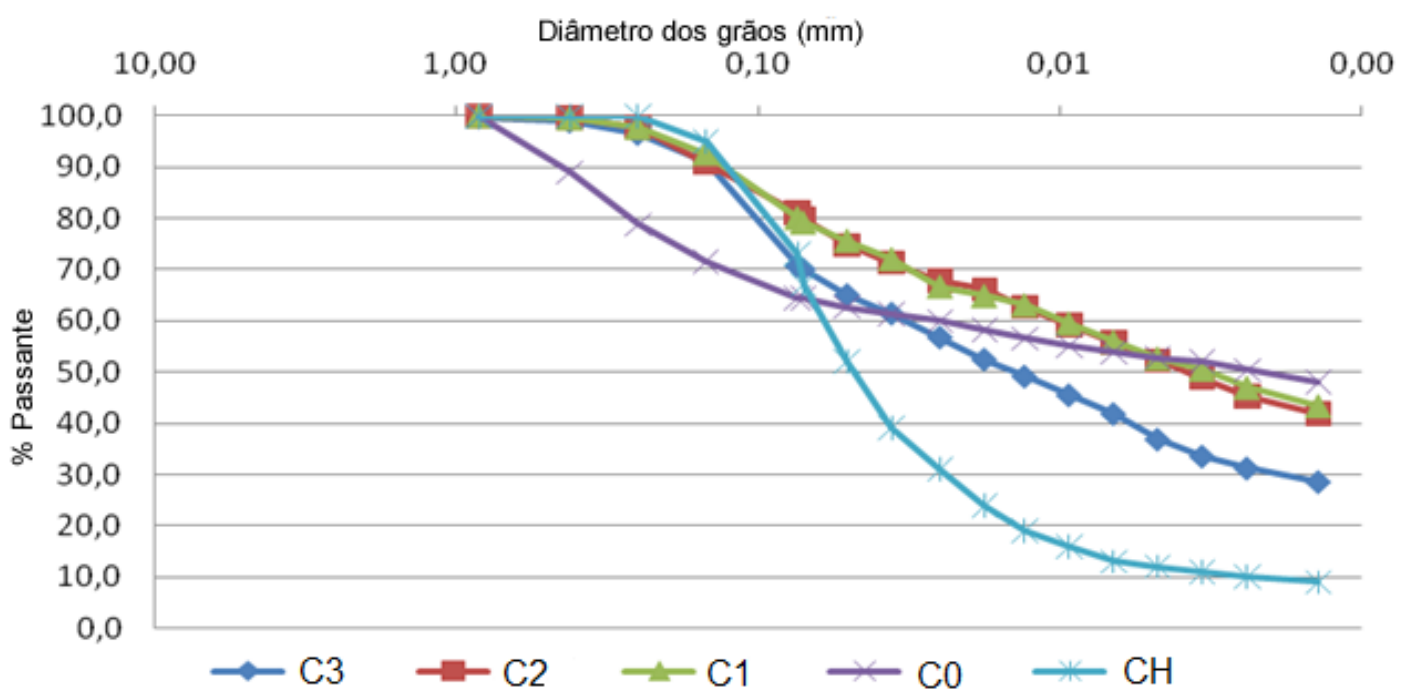

Figura 1 - Distribuição granulométrica das composições

\subsection{Limite de Atterberg}

De acordo com a tabela IV, conclui-se que o material (argila), é um material com plasticidade elevada, contudo se enquadrando no limite que é entre $10 \%$ a $35 \%$ [2]. Conclui-se também que o chamote não apresentou plasticidade, portanto se enquadra como um material não-plástico. Para as composições C1, C2 e C3, os resultados de LP são respectivamente 29,3; 30,6 e 26,6, onde o menor LP foi obtido para C3.

Tabela IV - Limite de Atterberg

\begin{tabular}{|c|c|c|c|c|}
\hline Série & $\begin{array}{c}\% \text { de } \\
\text { argila }\end{array}$ & LL & LP & IP \\
\hline C3 & 70 & 40,8 & 26,6 & 14,2 \\
\hline C2 & 80 & 44,8 & 30,6 & 14,1 \\
\hline C1 & 90 & 43,9 & 29,3 & 14,6 \\
\hline C0 & 100 & 52,2 & 27,0 & 25,2 \\
\hline CH & 0 & - & NP & NP \\
\hline
\end{tabular}

\subsection{Propriedades físico-mecânicas}

\subsubsection{Absorção de água}

A NBR 15270-1 [3] firma os requisitos físicos e mecânicos exigíveis em blocos cerâmicos, o índice de absorção de água (AA), deve ser menor que 22\%. De acordo com a figura 2, que relaciona a absorção de água, composição das amostras e a temperatura, apenas as amostras $\mathrm{C} 0, \mathrm{C} 1$ e $\mathrm{C} 2$ a $950^{\circ} \mathrm{C}$, atendem aos requisitos de norma. Nota-se a tendência de aumento de AA com a incorporação de chamote e a redução na AA com o aumento da temperatura, fato já observado por $[4,5]$. Analisando a influência da temperatura de queima, 850 e $950^{\circ} \mathrm{C}$, no comportamento das amostras, pode-se observar uma similaridade nos resultados, sendo a temperatura de $950^{\circ} \mathrm{C}$ a que leva a menores índices de $A A$. O aumento da 
temperatura, potencializa a fusão de óxidos fundentes presente nas massas, com consequente preenchimento de poros, ocasionando assim uma redução da AA através da redução da porosidade [6]. Com a incorporação do chamote a AA se mantém praticamente constante entre $\mathrm{C} 0$ e $\mathrm{C} 1$, a partir daí a um crescimento da $\mathrm{AA}$, sendo o maior valor para C3. A incorporação do chamote leva a um aumento de poros, pois este já foi sinterizado, eliminando-se totalmente sua água intersticial e prejudicando uma melhor aglomeração das partículas.

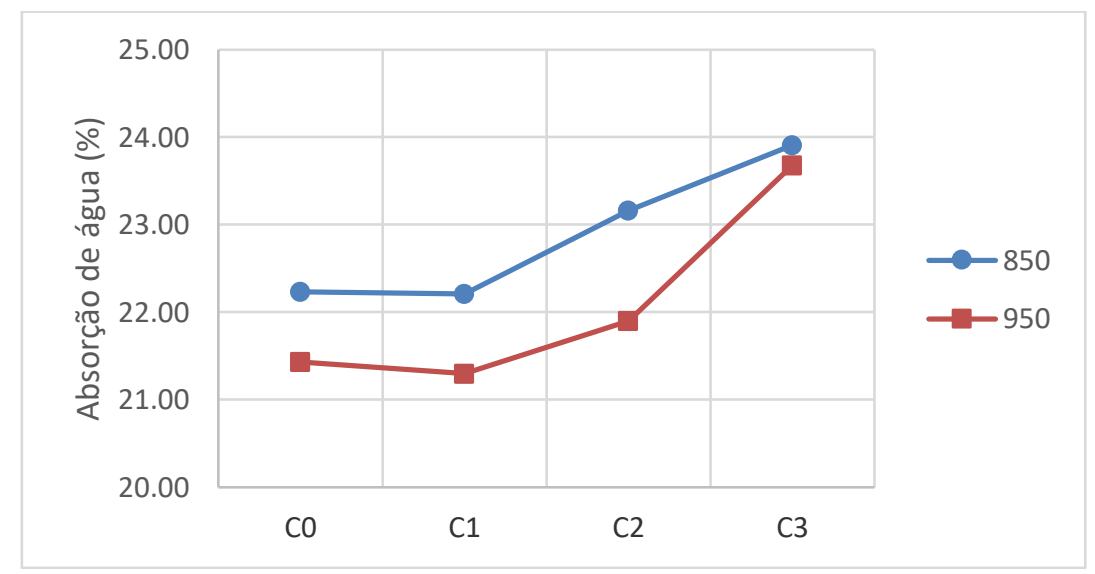

Figura 2: Absorção de água das diferentes composições.

\subsubsection{Retração linear por secagem, por queima e perda ao fogo.}

Os resultados da figura 3, indicam uma tendência de queda das retrações por secagem (RLS) e por queima (RLQ) de acordo com a incorporação do chamote, com o menor percentual para C3. Em relação a RLS a adição de material não-plástico (chamote) à massa cerâmica reduz a sua demanda por água e consequente umidade, há também uma menor interação entre o chamote e a água, causando pontos de descontinuidade nas forças de coesão entre as partículas, tanto no sentido horizontal como no vertical. Os pontos de descontinuidade produzem os poros que facilitam a passagem da água do interior até a superfície da peça, facilitando a secagem, reduzindo as contrações [5,7]. Na RLQ o efeito da incorporação do chamote não é tão visível, mas observa-se que para todas as composições, ocorreu acréscimo da retração, com o aumento da temperatura de queima. Este comportamento pode estar relacionado ao maior grau de sinterização, gerado pelo aumento da temperatura, provocando mudanças físicas e redução do volume dos corpos de prova, fato já observado por [6]. A redução na retração é de extrema importância para controlar a dimensão final da peça cerâmica e combater trincas e fissuras. 


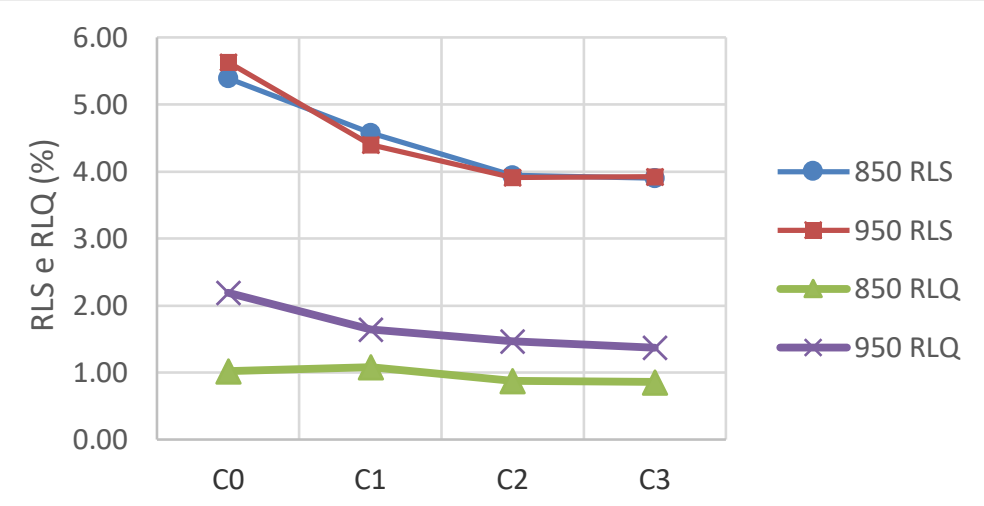

Figura 3 - Retração linear por secagem e por queima das composições.

Os resultados da figura 4, demonstram uma redução da perda ao fogo com o aumento da incorporação do chamote, este fato pode ser devido ao chamote já ter sofrido sinterização, sendo esta com temperatura de patamar a $850^{\circ} \mathrm{C}$. As temperaturas de queima estudadas estão próximas a de sinterização do chamote, reduzindo a volatilidade de seus componentes, a sua incorporação à massa cerâmica reduz a perda desta ao fogo. Para as diferentes composições o aumento da temperatura não influenciou de forma significativa na perda ao fogo, em virtude das transformações de decomposição que ocorrem durante as etapas de aquecimento e queima, possivelmente, estarem fora dos intervalos de temperatura estudados.

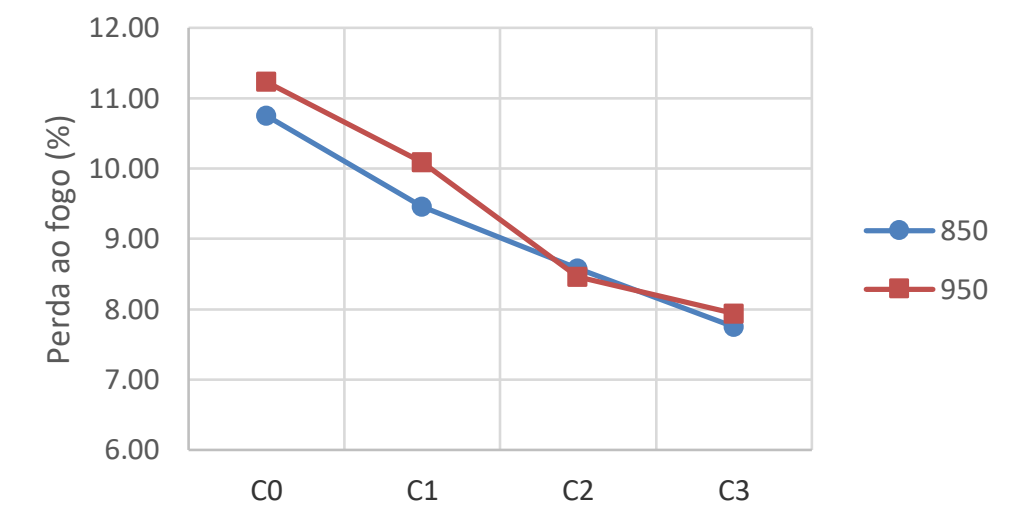

Figura 4 - Perda ao fogo das composições.

\subsubsection{Tensão de ruptura à flexão}

Os valores médios da tensão de ruptura a flexão, de acordo com a figura 5 , mostram uma tendência de queda da resistência com o aumento da incorporação do chamote, e um aumento de resistência com o aumento da temperatura, resultados similares foram encontrados por [5]. Os resultados da análise da tensão de ruptura estão intrinsecamente ligados à quantidade de poros existente no corpo cerâmico. Com o aumento da temperatura de queima, se melhora o grau de sinterização das partículas que compõem as massas cerâmicas e se reduz a porosidade pela formação de fase líquida que, durante o processo de sinterização, penetra nos poros existentes, densificando o material, com isso, melhorando a resistência pela redução 
da porosidade [6]. A incorporação do chamote acarreta uma menor disponibilidade de material (argila) passível de vitrificação, exceto a temperaturas superiores às estudadas, logo, há a queda da resistência com o aumento da incorporação do chamote, fato também observado por $[5,8]$. Todas as composições apresentaram valores superiores a 5,5 $\mathrm{MPa}$, valor recomendado para a tensão de ruptura após a sinterização na confecção de blocos cerâmicos [9].

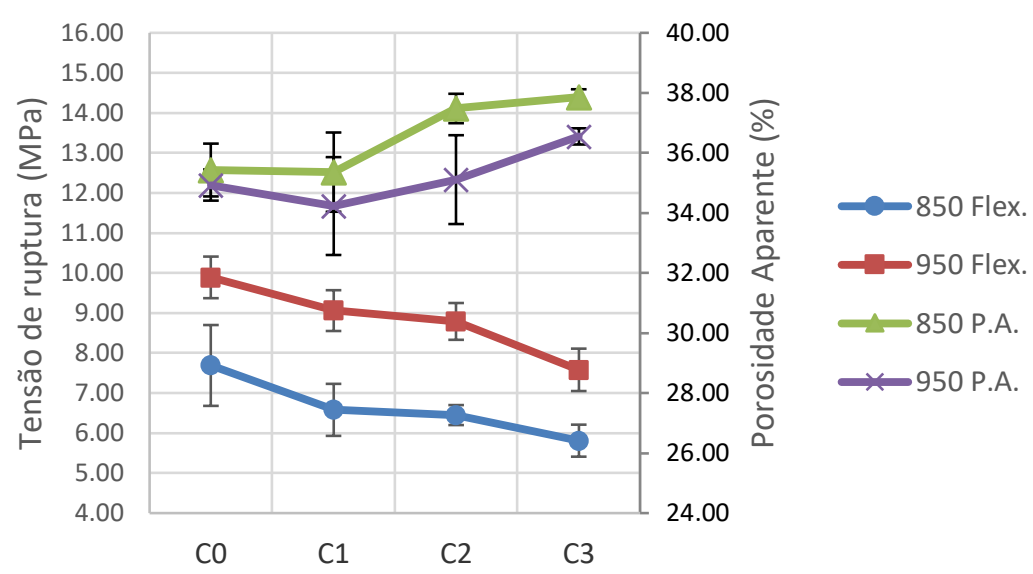

Figura 5 - Tensão de ruptura à flexão das diferentes composições.

\section{CONCLUSÃO}

A análise dos resultados do trabalho, conduz às principais conclusões:

a) as composições $\mathrm{C} 0, \mathrm{C} 1, \mathrm{C} 2$ à $950^{\circ} \mathrm{C}$ foram as únicas à atenderem os requisitos de norma, quanto a absorção de água, a melhora deste parâmetro passa pelo aumento da temperatura de sinterização.

b) a incorporação de chamote, em todos os casos, levou a uma redução da retração linear por secagem e da retração linear por queima, a redução destes parâmetros é de suma importância na indústria cerâmica, pois potencializa o controle de defeitos (trincas, fissuras, empenamentos, deformações, etc.) e a dimensão final da peça.

c) o aumento da porosidade aparente, com a incorporação do chamote, levou a um decréscimo na tensão de ruptura à flexão, mas ainda assim, todas as composições apresentaram valores superiores aos recomendados na literatura.

Conclui-se que o uso do chamote para incorporação em massas cerâmicas, permite obter materiais com boa resistência mecânica, moderada absorção de água e com boas propriedades dimensionais (retração linear e de queima baixas). Demonstra também ser uma alternativa economicamente viável, pois reutiliza um resíduo, e eficiente para a diminuição de problemas ambientais causados pelo seu descarte.

\section{Agradecimentos}

Os autores agradecem a UENF e FAPERJ pela estrutura e apoio financeiro, e a indústria cerâmica Sardinha, pelo fornecimento da argila e do chamote.

\section{REFERÊNCIAS}


1 Petrucci EGR. Materiais de construção. 10ª Ed. São Paulo: Globo; 1998.

2 Caputo HP. Mecânica dos solos e suas aplicações. Vol 1. 6” Ed. Rio de Janeiro: Livros Técnicos e Científicos; 1988.

3 Associação Brasileira de Normas Técnicas - ABNT. NBR 15270-1. Componentes cerâmicos parte 1: Blocos cerâmicos para alvenaria de vedação - Terminologia e requisitos". Rio de Janeiro, RJ; 2005.

4 Demir I., Orhan M. Reuse of waste bricks in the production line. Building Environment. 2003; 38 (12): 1451-1455.

5 Candido VS. Utilização de argilito e chamote de blocos de vedação na composição de massa de pavimento intertravado cerâmico - adoquim [dissertação de mestrado]. Campos dos Goytacazes: Universidade estadual do norte fluminense - UENF; 2012.

6 Porto VS, Silva MF, Cruz TB, Cavalcanti MSL, Silva CR. Obtenção e avaliação das propriedades físico-mecânica de massas cerâmicas para grés sanitários utilizando resíduo de vidro plano em sua composição. Revista Eletrônica de Materiais e Processos. 2012; 7(1): 13-19.

7 Pracidelli S, Melchiades FG. Importância da composição granulométrica de massas para a cerâmica vermelha. Cerâmica Industrial. 1997; 2(1): 31-35.

8 Gouveia FP, Sposto RM. Incorporação de chamote em massa cerâmica para a produção de blocos. Um estudo das propriedades físico-mecânicas. Cerâmica. 2009; 55(336): 415-419.

9 Santos PS. Ciência e Tecnologia de argilas 2ª Ed. São Paulo: Edgard Blücher; 1989. 